\title{
PEGylation, increasing specific activity and multiple dosing as strategies to improve the risk- benefit profile of targeted radionuclide therapy with ${ }^{177}$ Lu-DOTA-bombesin analogues
}

Simone Däpp ${ }^{1}$, Cristina Müller ${ }^{1}$, Elisa García Garayoa', Peter Bläuenstein', Veronique Maes², Luc Brans², Dirk A Tourwé ${ }^{2}$ and Roger Schibli, ${ }^{1,}$

\begin{abstract}
Background: Radiolabelled bombesin (BN) conjugates are promising radiotracers for imaging and therapy of breast and prostate tumours, in which $\mathrm{BN}_{2}$ /gastrin-releasing peptide receptors are overexpressed. We describe the influence of the specific activity of a ${ }^{177}$ Lu-DOTA-PEG ${ }_{5 k}$-Lys-B analogue on its therapeutic efficacy and compare it with its non-PEGylated counterpart.

Methods: Derivatisation of a stabilised DOTA-BN(7-14) $\left[\mathrm{Cha}^{13}, \mathrm{Nle}^{14}\right]$ analogue with a linear PEG molecule of $5 \mathrm{kDa}$ $\left(P E G_{5 k}\right.$ ) was performed by PEGylation of the $\epsilon$-amino group of a $\beta^{3} h L y s-\beta A l a-\beta A l a$ spacer between the BN sequence and the DOTA chelator. The non-PEGylated and the PEGylated analogues were radiolabelled with ${ }^{177} \mathrm{Lu}$. In vitro evaluation was performed in human prostate carcinoma PC-3 cells, and in vivo studies were carried out in nude mice bearing PC-3 tumour xenografts. Different specific activities of the PEGylated BN analogue and various dose regimens were evaluated concerning their therapeutic efficacy.

Results: The specificity and the binding affinity of the $\mathrm{BN}$ analogue for $\mathrm{BN}_{2} / \mathrm{GRP}$ receptors were only slightly reduced by PEGylation. In vitro binding kinetics of the PEGylated analogue was slower since steady-state condition was reached after $4 \mathrm{~h}$. PEGylation improved the stability of BN conjugate in vitro in human plasma by a factor of 5.6. The non-PEGylated BN analogue showed favourable pharmacokinetics already, i.e. fast blood clearance and renal excretion, but PEGylation improved the in vivo behaviour further. One hour after injection, the tumour uptake of the $P E G_{5 k}-B N$ derivative was higher compared with that of the non-PEGylated analogue $(3.43 \pm 0.63 \%$ vs. $1.88 \pm 0.4 \% \mathrm{ID} / \mathrm{g}$ ). Moreover, the increased tumour retention resulted in a twofold higher tumour accumulation at $24 \mathrm{~h}$ p.i., and increased tumour-to-non-target ratios (tumour-to-kidney, 0.6 vs. 0.4; tumour-to-liver, 8.8 vs. 5.9, 24 h p.i.). In the therapy study, both ${ }^{177}$ Lu-labelled BN analogues significantly inhibited tumour growth. The therapeutic efficacy was highest for the PEGylated derivative of high specific activity administered in two fractions $(2 \times 20 \mathrm{MBq}=40 \mathrm{MBq})$ at day 0 and day 7 (73\% tumour growth inhibition, 3 weeks after therapy).

Conclusions: PEGylation and increasing the specific activity enhance the pharmacokinetic properties of a ${ }^{177}$ Lu-labelled BN-based radiopharmaceutical and provide a protocol for targeted radionuclide therapy with a beneficial anti-tumour effectiveness and a favourable risk-profile at the same time.
\end{abstract}

Keywords: Gastrin-releasing peptide, Prostate cancer, ${ }^{177} \mathrm{Lu}$, Radionuclide therapy, PEGylation

\footnotetext{
* Correspondence: roger.schibli@psi.ch

${ }^{1}$ Paul Scherrer Institute, Center for Radiopharmaceutical Sciences ETH-PSI-

USZ, Villigen-PSI 5232, Switzerland

${ }^{3}$ Department of Chemistry and Applied Biosciences, ETH Zurich, Zurich 8093,

Switzerland

Full list of author information is available at the end of the article
} 


\section{Background}

Prostate and breast cancers are the most frequently diagnosed forms of cancer in the USA. Especially in addressing metastatic and small-volume diseases, it is essential to investigate, alongside conventional therapies, alternative treatments, such as peptide receptor radionuclide therapy (PRRT). The fact that certain tumour types overexpress, receptors for peptide-hormones provide the basis for successful use of radiolabelled peptide analogues as tumour tracers in nuclear medicine. The mammalian gastrin-releasing peptide receptor $\left(\mathrm{BN}_{2} / \mathrm{GRP}\right)[1,2]$ is particularly overexpressed in several human tumours, including prostate, breast and smallcell lung cancers [3-5]. The tetradecapeptide bombesin (BN) shows high binding affinity for these $\mathrm{BN}_{2} / \mathrm{GRP}$ receptors. Using $\mathrm{BN}$ conjugates for specific delivery of radionuclides into the above-mentioned tumours is therefore a promising strategy for diagnostic and therapeutic purposes.

BN analogues, however, present certain problems regarding therapy. They show poor enzymatic stability in vivo, which might prevent sufficient localisation at the target site. Furthermore, high accumulation and retention in healthy organs, which express the $\mathrm{BN}_{2} / \mathrm{GRP}$ receptor, increase the risk of side effects. Moreover, kidney toxicity, which was observed and investigated in PRRT with somatostatin analogues in clinical studies [6-8], may also hold true for $\mathrm{BN}$ analogues. Finally, several side effects were elicited from intravenous (i.v.) injection of BN agonists in humans. Therefore, a high specific activity of the radiolabelled $\mathrm{BN}$ agonist may be important in minimising such undesired effects.

Until now, the research has focused on optimising BN conjugates for nuclear imaging of cancer which overexpresses $\mathrm{BN}_{2} / \mathrm{GRP}$ receptors. Different $\mathrm{BN}$ analogues were labelled with diagnostic single-photon emission computed tomography (SPECT) and positron emission tomography (PET) radionuclides, such as ${ }^{111} \mathrm{In}$ [9-11], ${ }^{99 \mathrm{~m}} \mathrm{Tc}$ [12-15], ${ }^{18} \mathrm{~F}[16-18],{ }^{68} \mathrm{Ga}[19,20]$ and ${ }^{64} \mathrm{Cu}[21]$, and were evaluated in preclinical studies for their ability to detect $\mathrm{BN}_{2} /$ GRP receptor-positive lesions. However, only a few radiolabelled $\mathrm{BN}$ analogues have been tested in clinics on their diagnostic potential $[20,22]$. So far, only three $B N$ analogues, AMBA, DOTA-8-AOC-BN(7-14) $\mathrm{NH}_{2}$ and DOTAPESIN, have been rated in preclinical investigations on their potential for radionuclide therapy [23-25]. They were radiolabelled with ${ }^{177} \mathrm{Lu}$ (beta-emitter, $\mathrm{E}_{\beta}{ }^{-}{ }_{\max } 0.497 \mathrm{MeV}$, half-life of 6.7 days) or with ${ }^{213} \mathrm{Bi}$ (alpha-emitter, $\mathrm{E}_{\beta}{ }^{-}$max 1.423 MeV, $\mathrm{E}_{\alpha \max } 5.982 \mathrm{MeV}$, half-life of $45.6 \mathrm{~min}$ ). The in vitro and in vivo evaluations of our ${ }^{177} \mathrm{Lu}$-DOTA-Lys$\mathrm{BN}$ analogue (DOTA- $\beta^{3}$ hLys- $\beta$ Ala- $\beta$ Ala-Gln ${ }^{7}-\mathrm{Trp}^{8}$-Ala ${ }^{9}-$ $\mathrm{Val}^{10}{ }^{10} \mathrm{Gly}^{11}$-His ${ }^{12}-\mathrm{Cha}^{13}-\mathrm{Nle}^{14}-\mathrm{NH}_{2}$ ) showed pharmacokinetic properties which are comparable to that reported for the above-mentioned $\mathrm{BN}$ analogues. Therefore, we wanted to improve the radiotherapy-relevant characteristics further by PEGylating ${ }^{177}$ Lu-DOTA-Lys-BN.

Our preclinical study with a series of ${ }^{99 \mathrm{~m}} \mathrm{Tc}(\mathrm{CO})_{3^{-}}$ labelled PEGylated BN analogues showed that PEGylation is an effective strategy to improve the therapy-relevant characteristics, which include higher tumour uptake, improved tumour retention and lower uptake into nontarget tissue. The PEG entity of $5 \mathrm{kDa}$ was established as the optimal PEG size because it improved these features best [26].

The BN analogues of the current study were therefore based on one of our stabilised analogues $\left(\mathrm{Gln}^{7}-\operatorname{Trp}^{8}\right.$ $\mathrm{Ala}^{9}-\mathrm{Val}^{10}-\mathrm{Gly}^{11}-\mathrm{His}^{12}-\mathrm{Cha}^{13}-\mathrm{Nle}^{14}-\mathrm{NH}_{2}$ ) containing a $\beta^{3}$ hLys- $\beta$ Ala- $\beta$ Ala spacer (Figure 1) [14]. The peptide was equipped with a 1,4,7,10-tetraazacyclododecane-1,4,7,10tetraacetic acid (DOTA) chelator to provide the analogue DOTA- $\beta^{3}$ hLys- $\beta$ Ala- $\beta$ Ala-Gln ${ }^{7}-\mathrm{Trp}^{8}-\mathrm{Ala}^{9}-\mathrm{Val}^{10}{ }^{10} \mathrm{Gly}^{11}$ $\mathrm{His}^{12}-\mathrm{Cha}^{13}-\mathrm{Nle}^{14}-\mathrm{NH}_{2}$ (referred to as DOTA-Lys-BN, Figure 1a). We hypothesised that PEGylating this DOTALys-BN would lead to the same favourable characteristics seen with PEGylated ${ }^{99 \mathrm{~m}}$ Tc-based BN analogues. Derivatisation of the DOTA-Lys-BN analogue with a linear PEG molecule of $5 \mathrm{kDa}\left(\mathrm{PEG}_{5 \mathrm{k}}\right)$ was performed by PEGylation of the $\epsilon$-amino group of the lysine residue. The resulting PEGylated BN (referred to as DOTA-PEG 5 k-Lys-BN, Figure $1 \mathrm{~b}$ ) as well as the DOTA-Lys-BN were then radiolabelled with ${ }^{177} \mathrm{Lu}$. We chose this radionuclide because it is currently used together with ${ }^{90} \mathrm{Y}$ for PRRT with somatostatin analogues on a routine basis in clinics $[27,28]$ and because it proved to be less problematic concerning kidney toxicity in comparison with the ${ }^{90}$ Y-radiolabelled somatostatin analogue [8,27]. Furthermore, application of ${ }^{177} \mathrm{Lu}$ allows imaging and PRRT at the same time owing to $\gamma$-ray emissions of suitable energy for SPECT, which enables dosimetry calculations and therapy monitoring [29].

In the current study, the new ${ }^{177} \mathrm{Lu}$-labelled DOTALys-BN and DOTA-PEG Fk -Lys-BN analogues were tested in vitro in human prostate carcinoma PC-3 cells and in $\mathrm{PC}-3$ tumour bearing mice. They were compared in order to evaluate the effect of PEGylation on in vivo pharmacokinetics and their therapeutic effectiveness. Apart from looking at the anti-tumour efficacy, we also investigated the optimal risk-benefit profile by varying the specific activity of the radiolabelled DOTA-PEG ${ }_{5 \mathrm{k}^{-}}$ Lys-BN analogue and assessed the efficacy of PRRT by varying the number and the interval of the ${ }^{177} \mathrm{Lu}-$ DOTA-PEG ${ }_{5 \mathrm{k}}-\mathrm{BN}$ doses. For an estimation of potential kidney toxicity, the renal function was monitored with quantitative ${ }^{99 \mathrm{~m}} \mathrm{Tc}-\mathrm{DMSA}$ scintigraphy.

\section{Methods}

Sources of materials, equipment, peptide synthesis and PEGylation are presented in Additional file 1. 

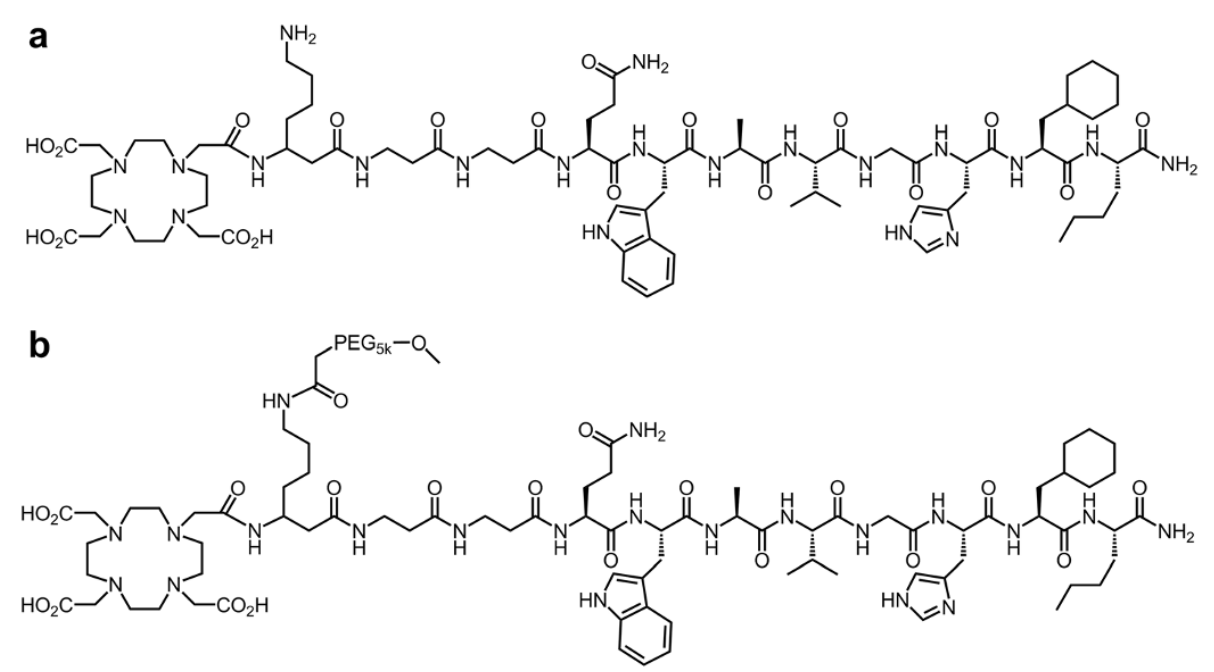

Figure 1 Chemical structures of (a) DOTA-Lys-BN and (b) DOTA-PEG ${ }_{5 k}-$ Lys-BN analogues.

\section{Statistical analysis}

All data are presented as mean $\pm \mathrm{SD}$. The in vivo data were statistically analysed with a $t$ test (Microsoft Excel software). All analyses were 2-tailed and considered as type 3 (two-sample unequal variance); $P<0.05$ was considered statistically significant.

\section{${ }^{177}$ Lu labelling of the DOTA-lys-BN and DOTA-PEG 5 -lys- BN analogues}

For high specific activity labelling, $16 \mu \mathrm{l}$ of approximately $400 \mathrm{MBq}{ }^{177} \mathrm{LuCl}_{3}(714.3 \mathrm{GBq} / \mu \mathrm{mol})$ were added to a mixture of $20 \mu \mathrm{l}$ ammonium acetate solution (0.5 M, pH 7.5), 84 $\mu \mathrm{l} \mathrm{HCl}(0.04 \mathrm{M}), 5 \mu \mathrm{l}$ ascorbic acid solution $(0.05 \mathrm{M})$ and $5.6 \mathrm{nmol}$ of $\mathrm{BN}$ analogue (high specific, $66 \mathrm{MBq} / \mathrm{nmol}$ peptide). The final solution ( $\mathrm{pH}$ 4.5) was heated at $75{ }^{\circ} \mathrm{C}$ for $15 \mathrm{~min}$ (Additional file 1: Figure S7). For the ${ }^{177} \mathrm{Lu}$-labelled $\mathrm{BN}$ analogues of low specific activity $(6.6 \mathrm{MBq} / \mathrm{nmol}$ peptide), unlabelled $\mathrm{BN}$ analogue was added to the high specific labelling solution to reach the respective concentration.

\section{Metabolic stability in human plasma}

The labelled analogues were incubated with human plasma (final concentration, $10 \mathrm{MBq} / 0.6 \mathrm{ml}$ ) at $37{ }^{\circ} \mathrm{C}$ for various time intervals up to 12 days. After incubation, proteins were precipitated with acetonitrile/ethanol (1:1) and TFA $(0.1 \%)$ and then centrifuged. The supernatant was analysed with RP-high-performance liquid chromatography (HPLC) equipped with a radioactivity detector. The radioactivity chromatograms showed different peaks which corresponded to the intact peptide and the different degradation products. The experiments were performed two times.

\section{Internalisation and externalisation studies}

For internalisation, PC-3 cells at confluence were placed in six-well plates and left to attach overnight. Cells were incubated with the labelled analogues $(4 \mathrm{kBq})$ in culture medium for $0.5,1,2,4$ and $24 \mathrm{~h}$ at $37^{\circ} \mathrm{C}$. Non-specific binding was determined with $1 \mu \mathrm{M}$ unlabelled $\mathrm{BN}$ (1-14). After the different incubation times, cells were twice washed with cold phosphate buffered saline (PBS) to discard unbound peptide. Surface-bound activity was removed by two 5 -min acid washes $(50 \mathrm{mM}$ glycin$\mathrm{HCl}, 100 \mathrm{mM} \mathrm{NaCl}, \mathrm{pH} 2.8$ ). Afterwards, the cells were washed with cold PBS, and lysed with $1 \mathrm{~N} \mathrm{NaOH}$ twice. Surface-bound and internalised radioactivities were measured in the gamma counter.

For externalisation, $\mathrm{PC}-3$ cells were incubated with the labelled analogues $(60 \mathrm{kBq})$ in culture medium at $37{ }^{\circ} \mathrm{C}$ for $1 \mathrm{~h}$. After incubation, the supernatant was discarded, and the cells were twice washed with cold PBS. The cells were then incubated again at $37{ }^{\circ} \mathrm{C}$ in culture medium for $0.5,1,2.5,5$ and $24 \mathrm{~h}$. At each time point, the supernatant was collected, the cells twice washed with cold PBS and lysed with $1 \mathrm{~N} \mathrm{NaOH}$. The supernatant (released radioactivity) and the cells (bound/internalised radioactivity) were measured in the gamma counter. All experiments were carried out two to three times in triplicate.

\section{Biodistribution studies}

All animal experiments were conducted in compliance with the Swiss animal protection laws and with the ethical principles and guidelines for scientific animal experimentation established by the Swiss Academy of Natural Sciences. Biodistribution studies were performed with 6- to 8-week-old female CD-1 nu/nu mice (20 to 
25 g) purchased from Charles River Laboratories (Sulzfeld, Germany). For the induction of tumour xenografts, each mouse received subcutaneously $8 \times 10^{6}$ PC-3 cells in $150 \mu \mathrm{l}$ culture medium without supplements. The tumours were allowed to grow for at least 3 weeks. On the day of the experiment, the mice (3 to 6 per group) received the radioactive conjugates intravenously. For the biodistribution studies, the mice were injected with different specific activities of the radiolabelled $\mathrm{BN}$ analogues (low specific, 6.6 MBq/nmol peptide; high specific, $66 \mathrm{MBq} / \mathrm{nmol}$ peptide). Receptor-blocking studies were performed using $100 \mu \mathrm{g}$ of unlabelled BN (1-14) co-injected with the corresponding radiolabelled BN analogue. At 1, 4 and $24 \mathrm{~h}$ post injection (p.i.), the animals were euthanised and dissected. Blood, tumours and various healthy tissues and organs were collected, weighed and examined for radioactivity. Results are expressed as percentage of injected dose per gram of tissue $(\% \mathrm{ID} / \mathrm{g})$.

\section{Dose calculation}

The absorbed doses to PC-3 tumours and critical organs were calculated from the biodistribution studies ( $1 \mathrm{MBq} / 0.1 \mathrm{ml}$; 0.3 or $3.0 \mathrm{nmol}$ peptide; $n=3$ per group). Under the assumption of rapid accumulation (uptake at $0 \mathrm{~h}$ p.i. corresponds to the uptake at $1 \mathrm{~h}$ p.i.), the cumulative radioactivity in each tissue was calculated $(\mathrm{MBq} / \mathrm{h})$ taking biologic elimination and physical decay into account up to $24 \mathrm{~h}$ p.i. and afterwards only physical decay up to $400 \mathrm{~h}$ p.i. The absorbed tumour doses of the mouse experiments were extrapolated from the sphere model doses which were calculated by using the software OLINDA (OLINDA/EXM1.0, Vanderbilt University, Nashville, TN, USA). The $S$ values for all other tissues of mice were taken from E Larsson [30]. The absorbed dose (milligray per mega-Bequerel) was calculated by multiplying the area under the curve (AUC) ( $h$; normalised to $1 \mathrm{MBq}$ ID) with the $S$ value $\left(\mathrm{mGy} /\left(\mathrm{MBq}^{\star} \mathrm{s}\right)\right)$. The dose (in Gy) was calculated by multiplying the absorbed dose (mGy/MBq) with the amount of radioactivity injected (20 MBq). The AUC-estimate for an adult male was obtained by multiplying the AUC of the mice $(\mathrm{MBq} / \mathrm{h})$ with a factor consisting of (total body weight mouse $_{\text {/total }}$ body weight $\left.t_{\text {adult male }}\right) \times$ organ weight $t_{\text {adult male. }}$ The subsequent dose calculation was performed using the adult male model of the software OLINDA.

\section{Therapy studies}

Therapy studies were conducted in mice bearing PC-3 xenografts. The tumour was assumed to be an ellipsoid, and its volume was calculated with the formula $V_{t}=(\pi / 6) L W^{2}$ where $L$ represents the longest dimension and $W$ the shortest dimension of the tumour.
Two weeks post PC-3 inoculation, i.e. the day of the first injection (day 0), the tumours had an average volume of $85 \mathrm{~mm}^{3}$. The animals were divided into six groups of six mice (Table 1). The control group received an i.v. injection of PBS only (group A). Another group was injected with unlabelled DOTA$\mathrm{PEG}_{5 \mathrm{k}}$-Lys-BN at a peptide amount of $3.0 \mathrm{nmol}$ (group $B)$. The treated mice received two equal doses of $20 \mathrm{MBq}$ i.v. either of ${ }^{177}$ Lu-DOTA-PEG $5 \mathrm{k}$-Lys-BN (groups $\mathrm{C}$ to $\mathrm{E}$ ) or of ${ }^{177} \mathrm{Lu}-\mathrm{DOTA}-\mathrm{Lys}-\mathrm{BN}$ (group F) at a peptide amount of 0.3 or $3.0 \mathrm{nmol}$. The injections were performed either at days 0 and 14 or at days 0 and 7 (Table 1). Body weight and tumour volume of all mice were quantified 3 times per week. The relative volume of tumours $V_{\mathrm{r}}$ was defined as $V_{\mathrm{r}}=V_{t} / V_{0}$, where $V_{t}$ was the measurement at time $t$ (days after the first injection), and $V_{0}$ was the measurement at day 0 . If a tumour disappeared, $V_{t}$ was set to 0 . Mice were removed from the study promptly upon fulfilling one or both of the following criteria: a tumour volume of $\geq 1.5 \mathrm{~cm}^{2}$ or total body weight loss of $\geq 15 \%$. Upon euthanasia, tumours were collected and embedded in TissueTek (Sakura Finetek, USA Inc., Torrance, CA, USA) and frozen for autoradiography.

\section{${ }^{99 m}$ TC-DMSA SPECT/CT imaging studies}

Three groups of four mice each (groups G to I, Table 1), which were not xenografted with $\mathrm{PC}-3$ cells, were included in the therapy study for ${ }^{99 \mathrm{~m}} \mathrm{Tc}$-DMSA tests. An untreated control group of mice (group G), a treated group receiving two doses of the ${ }^{177} \mathrm{Lu}-\mathrm{DOTA}-\mathrm{PEG}_{5 \mathrm{k}^{-}}$ Lys-BN analogue at high specific activity (group $\mathrm{H}$ ) and a treated group of mice getting two doses of the ${ }^{177} \mathrm{Lu}-$ DOTA-PEG ${ }_{5 \mathrm{k}}$-Lys-BN analogue with low specific activity (group I). ${ }^{99 \mathrm{~m}} \mathrm{Tc}-\mathrm{DMSA}$ scans with $\mathrm{SPECT} / \mathrm{computed}$ tomography $(\mathrm{CT})$ were obtained 43,71 and 111 days after therapy, $2 \mathrm{~h}$ after i.v. injection of about $30 \mathrm{MBq}$ ${ }^{99 \mathrm{~m}}$ Tc-DMSA. SPECT scans were acquired with anaesthetised mice during $20 \mathrm{~min}$ using 15 projections/min. The images were obtained on an X-SPECT-system (Gamma Medica, Inc., Northridge, CA, USA) equipped with a single head SPECT device and a CT device. SPECT data were acquired and reconstructed with LumaGEM (version 5.407, Gamma Medica, Northridge, CA, USA). CT data were acquired with an X-ray CT-system (Gamma Medica) and reconstructed with the software CoBRA (version 4.5.1, Falls Church, VA, USA). SPECT and CT data were combined with the software IDL Virtual Machine (version 6.0, Exelis Visual Information Solutions, Inc., McLean, VA, USA). The images were generated with Amira (version 4.0). Quantification of the amount of radioactivity in a volume of interest over the kidneys was performed with Amira (version 4.0, 
Table 1 Therapy protocol: classification of therapy groups and specification of administration of the BN analogues

\begin{tabular}{|c|c|c|c|c|}
\hline Therapy groups & & BN analogues & Dose and peptide amount & Injection time \\
\hline \multirow[t]{6}{*}{ Mice with PC-3 tumour xenografts } & A & PBS & $2 \times 100 \mu l$ & Days 0 and 14 \\
\hline & B & DOTA-PEG ${ }_{5 k}-$ Lys-BN & $2 \times 3.0 \mathrm{nmol}$ & Days 0 and 14 \\
\hline & C & ${ }^{177}$ Lu-DOTA-PEG 5 -Lys-BN & $2 \times 20 \mathrm{MBq} / 3.0 \mathrm{nmol}$ each & Days 0 and 14 \\
\hline & $\mathrm{D}$ & ${ }^{177}$ Lu-DOTA-PEG ${ }_{5 k}$-Lys-BN & $2 \times 20 \mathrm{MBq} / 0.3 \mathrm{nmol}$ each & Days 0 and 14 \\
\hline & $E$ & ${ }^{177}$ Lu-DOTA-PEG 5 -Lys-BN & $2 \times 20 \mathrm{MBq} / 0.3 \mathrm{nmol}$ each & Days 0 and 7 \\
\hline & $\mathrm{F}$ & ${ }^{177}$ Lu-DOTA-Lys-BN & $2 \times 20 \mathrm{MBq} / 0.3 \mathrm{nmol}$ each & Days 0 and 14 \\
\hline \multirow[t]{3}{*}{ Mice without PC-3 tumour xenografts } & G & PBS & $2 \times 100 \mu \mathrm{l}$ & Days 0 and 14 \\
\hline & $\mathrm{H}$ & ${ }^{177}$ Lu-DOTA-PEG 5 -Lys-BN & $2 \times 20 \mathrm{MBq} / 0.3 \mathrm{nmol}$ each & Days 0 and 14 \\
\hline & I & ${ }^{177}$ Lu-DOTA-PEG 5 -Lys-BN & $2 \times 20 \mathrm{MBq} / 3.0 \mathrm{nmol}$ each & Days 0 and 14 \\
\hline
\end{tabular}

San Diego, CA, USA). Detected counts in the volume of interest were normalised to $1 \mathrm{MBq}$ ID.

\section{Results and discussion \\ Results \\ In vitro evaluation}

The PEGylation of the DOTA-Lys-BN analogue (Additional file 1: Figure S7) as well as the results of the $\log D$ and $\mathrm{IC}_{50}$ determination are presented in Additional file 1. PEGylation resulted in a slightly increased hydrophilicity of the analogue and in an eightfold higher $\mathrm{IC}_{50}$ value compared with that of the non-PEGylated analogue $(15.96 \pm 4.42 \mathrm{nM}$ vs. $2.03 \pm 0.42 \mathrm{nM})$. The ${ }^{177} \mathrm{Lu}$-DOTA-Lys-BN was rapidly degraded by proteases in human plasma. After 5 days of incubation, it was almost entirely metabolised, and only $13.8 \pm 5.7 \%$ remained intact. PEGylation resulted in a marked increase in protease stability; $51.8 \pm 0.9 \%$ of ${ }^{177}$ Lu-DOTA-PEG ${ }_{5 k}$-Lys$\mathrm{BN}$ still remained intact after 5 days of incubation and $43.7 \pm 0.5 \%$ after 11 days. Moreover, the half-life of ${ }^{177} \mathrm{Lu}-$ DOTA-Lys-BN in human plasma was $1.2 \pm 0.3$ days, whereas the half-life of ${ }^{177} \mathrm{Lu}-\mathrm{DOTA}-\mathrm{PEG}_{5 \mathrm{k}}-\mathrm{Lys}-\mathrm{BN}$ was $6.7 \pm 1.4$ days (Figure 2).

${ }^{177}$ Lu-DOTA-Lys-BN internalised rapidly into PC-3 cells and reached its maximum within the first hour of incubation (approximately $30 \% / 10^{6}$ cells). The PEGylated analogue showed a significantly lower and slower internalisation into PC-3 cells. After incubation for $4 \mathrm{~h}$, the internalised fraction was $3.3 \pm 1.2 \%$. Externalisation studies revealed $63.1 \pm 4.0 \%$ of the internalised ${ }^{177} \mathrm{Lu}$ DOTA-Lys-BN externalised within the first $2.5 \mathrm{~h}$. After $24 \mathrm{~h}$, only $13.5 \pm 7.2 \%$ of the internalised fraction was found in the cells. In contrast, the externalisation of the PEGylated analogue was slower $(24.2 \pm 1.3 \%$ after $24 \mathrm{~h})$.

\section{Biodistribution studies}

The effect of PEGylation was tested in vivo in mice with PC-3 tumour xenografts performed with BN conjugates at an injected peptide amount of $0.075 \mathrm{nmol}$ (Table 2). The highest tumour uptake of ${ }^{177}$ Lu-DOTA-Lys-BN
$(1.88 \% \mathrm{ID} / \mathrm{g})$ and ${ }^{177} \mathrm{Lu}-\mathrm{DOTA}-\mathrm{PEG}_{5 \mathrm{k}}-\mathrm{Lys}-\mathrm{BN} \quad(3.43 \%$ $\mathrm{ID} / \mathrm{g}$ ) was found $1 \mathrm{~h}$ p.i., the latter being significantly higher. Thus, the enhanced enzymatic stability induced by PEGylation compensated for the lower receptor affinity of DOTA-PEG ${ }_{5 \mathrm{k}}$-Lys-BN. Furthermore, the tumour washout was slightly slower for the PEGylated analogue. Thus, $1.04 \% \mathrm{ID} / \mathrm{g}$ was found for the ${ }^{177} \mathrm{Lu}-\mathrm{DOTA}-$ PEG $_{5 \mathrm{k}}$-Lys-BN $24 \mathrm{~h}$ p.i., whereas only $0.54 \% \mathrm{ID} / \mathrm{g}$ of ${ }^{177} \mathrm{Lu}-\mathrm{DOTA}-\mathrm{Lys}-\mathrm{BN}$ remained in the tumour. At $1 \mathrm{~h} \mathrm{p}$. i., both analogues showed their highest uptake in the pancreas, which expresses GRP receptors (8.68\% ID/g and $9.62 \% \mathrm{ID} / \mathrm{g}$ for ${ }^{177} \mathrm{Lu}-\mathrm{DOTA}-\mathrm{Lys}-\mathrm{BN}$ and ${ }^{177} \mathrm{Lu}-$ DOTA-PEG ${ }_{5 \mathrm{k}}-\mathrm{Lys}-\mathrm{BN}$, respectively). The liver uptake of both ${ }^{177}$ Lu-DOTA-Lys-BN and ${ }^{177}$ Lu-DOTA-PEG $5 k^{-}$ Lys-BN was low $(0.26 \% \mathrm{ID} / \mathrm{g}$ and $0.57 \% \mathrm{ID} / \mathrm{g}$ at $1 \mathrm{~h}$ p.i., respectively). Kidney accumulation was higher for the ${ }^{177} \mathrm{Lu}-\mathrm{DOTA}-\mathrm{PEG}_{5 \mathrm{k}}$-Lys-BN in comparison with that of the non-PEGylated analogue at $1 \mathrm{~h}$ p.i. (4.89\% ID/g vs.

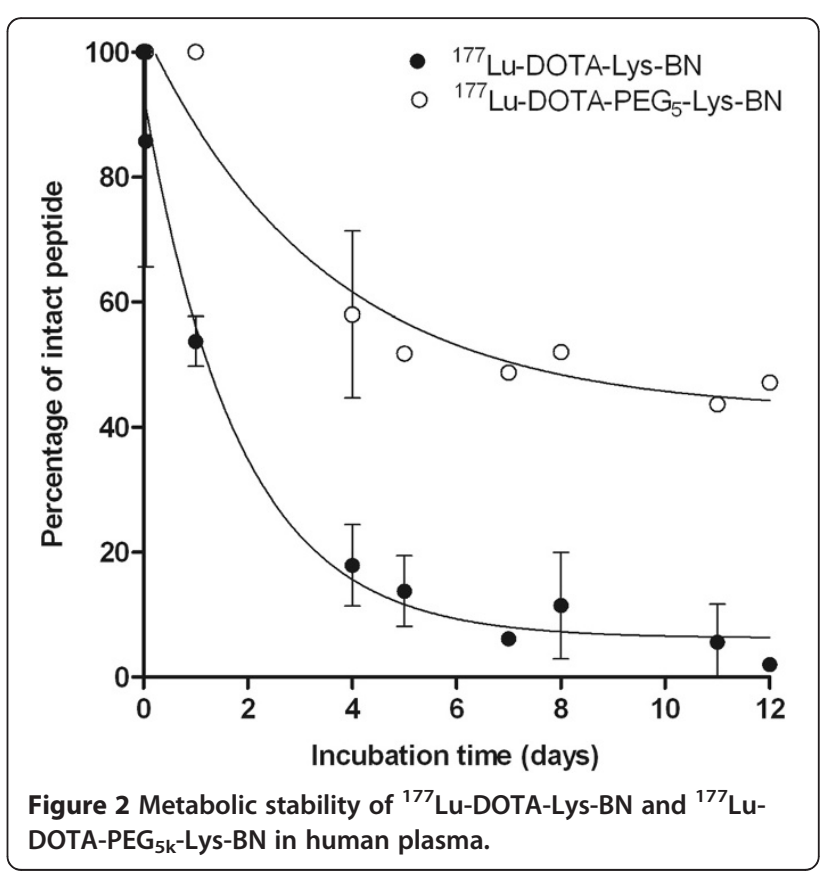


Table 2 Biodistribution (0.3 MBq/0.075 nmol) of ${ }^{177}$ Lu-labelled BN analogues in nude mice bearing PC-3 tumour

\begin{tabular}{|c|c|c|c|c|c|c|}
\hline \multirow[b]{2}{*}{ Tissue } & \multicolumn{2}{|c|}{${ }^{177}$ Lu-DOTA-Lys-BN } & \multicolumn{2}{|c|}{${ }^{177}$ Lu-DOTA-PEG $_{5 \mathrm{k}}$-Lys-BN } & \multirow{2}{*}{$\frac{{ }^{177} \text { Lu-DOTA-Lys-BN }}{1 \text { h p.i. blocked }}$} & \multirow{2}{*}{$\frac{{ }^{177} \text { Lu-DOTA-PEG }_{5 k} \text {-Lys-BN }}{1 \text { h p.i. blocked }}$} \\
\hline & 1 h p.i. & 24 h p.i. & 1 h p.i. & 24 h p.i. & & \\
\hline Blood & $0.24 \pm 0.07$ & $0.00 \pm 0.00$ & $1.54 \pm 0.33^{*}$ & $0.01 \pm 0.00^{*}$ & & \\
\hline Heart & $0.14 \pm 0.06$ & $0.01 \pm 0.01$ & $0.49 \pm 0.05$ & $0.04 \pm 0.01$ & & \\
\hline Lung & $0.36 \pm 0.08$ & $0.02 \pm 0.01$ & $1.10 \pm 0.15$ & $0.13 \pm 0.02$ & & \\
\hline Spleen & $0.42 \pm 0.12$ & $0.18 \pm 0.04$ & $0.72 \pm 0.02$ & $0.19 \pm 0.03$ & & \\
\hline Kidneys & $2.86 \pm 0.63$ & $1.41 \pm 0.14$ & $4.89 \pm 1.33$ & $1.84 \pm 0.52$ & & \\
\hline Pancreas & $8.68 \pm 1.95$ & $4.27 \pm 0.85$ & $9.62 \pm 2.39$ & $4.87 \pm 1.11$ & $0.49 \pm 0.22^{* *}$ & $0.98 \pm 0.59^{*}$ \\
\hline Stomach & $0.72 \pm 0.19$ & $0.10 \pm 0.02$ & $1.12 \pm 0.15$ & $0.22 \pm 0.07$ & & \\
\hline Small intestine & $1.38 \pm 0.41$ & $0.16 \pm 0.03$ & $1.18 \pm 0.22$ & $0.17 \pm 0.12$ & & \\
\hline Colon & $1.64 \pm 0.40$ & $0.36 \pm 0.09$ & $2.19 \pm 0.91$ & $0.45 \pm 0.21$ & $0.36 \pm 0.07^{* *}$ & $0.66 \pm 0.14$ \\
\hline Liver & $0.26 \pm 0.09$ & $0.09 \pm 0.02$ & $0.57 \pm 0.04$ & $0.16 \pm 0.09$ & & \\
\hline Muscle & $0.20 \pm 0.24$ & $0.01 \pm 0.00$ & $0.31 \pm 0.06$ & $0.42 \pm 0.69$ & & \\
\hline Bone & $0.36 \pm 0.24$ & $0.02 \pm 0.01$ & $0.70 \pm 0.06$ & $0.58 \pm 0.44$ & & \\
\hline Tumour & $1.88 \pm 0.47$ & $0.54 \pm 0.30$ & $3.43 \pm 0.63^{*}$ & $1.04 \pm 0.04$ & $0.55 \pm 0.03^{*}$ & $1.02 \pm 0.34^{* *}$ \\
\hline
\end{tabular}

${ }^{*} P<0.05 ;{ }^{* *} P<0.01$. Data in percentage of injected dose per gram of tissue (\%ID/g), expressed as mean \pm SD at 1 and $24 \mathrm{~h}$ p.i. ( $n=3$ to 4 ).

$2.86 \% \mathrm{ID} / \mathrm{g}$, respectively). The renal clearance, however, was fast for both analogues (1.84\% ID/g vs. $1.41 \% \mathrm{ID} / \mathrm{g}$ at $24 \mathrm{~h}$ p.i., respectively). The conjugation of a $\mathrm{PEG}_{5 \mathrm{k}}$ entity resulted in a significantly longer blood circulation during $1 \mathrm{~h}$ p.i., but both derivatives were completely cleared from blood within $24 \mathrm{~h}$ p.i. (Table 2).

Specificity for GRP receptors could be demonstrated by a co-administration of non-radioactive $\mathrm{BN}(1-14)$. Thus, only the uptake in the receptor-expressing tissues such as the pancreas, colon and tumour was markedly reduced $(>70 \%)$, whereas the inhibition was slightly less effective for the PEGylated BN analogue (Table 2).

The tumour-to-non-target ratios were similar for both derivatives. The initial longer circulation time of ${ }^{177} \mathrm{Lu}$ DOTA-PEG ${ }_{5 \mathrm{k}}$-Lys-BN, however, resulted in lower tumour-to-blood ratios at 1 and $4 \mathrm{~h}$ p.i. compared with that of the non-PEGylated compound. ${ }^{177} \mathrm{Lu}-\mathrm{DOTA}-$ PEG $_{5 \mathrm{k}}$-Lys-BN showed a twofold increase in the tumour-to-pancreas ratio at all time points and in tumour-to-kidney and tumour-to-liver ratios at $24 \mathrm{~h}$ p.i. (Figure 3).

In additional biodistribution studies, two ligand doses of the ${ }^{177}$ Lu-DOTA-PEG 5 k-Lys-BN at a peptide amount corresponding to the amount that was injected in the therapy studies (high specific, $0.3 \mathrm{nmol}$; or low specific, $3.0 \mathrm{nmol}$ peptide injected per mouse) were administered. This showed that the uptake in the receptor-expressing tissues such as the pancreas and colon was markedly reduced by applying a high amount of PEGylated peptide $(3.0 \mathrm{nmol})$. The tumour uptake was also reduced by $29 \%$ and $42 \%$ at $1 \mathrm{~h}$ p.i. and $24 \mathrm{~h}$ p.i. after injection of a high amount of peptide (Figure 4, Table 3). In comparison, the tumour-to-blood, tumour-to-liver, tumour-to-kidney and tumour-to-muscle ratios were approximately twofold higher at all time points if ${ }^{177}$ Lu-DOTA-PEG k -Lys-BN was injected at a low molar amount of peptide $(0.3 \mathrm{nmol})$. The only ratios which revealed a higher value with a high amount of peptide $(3.0 \mathrm{nmol})$ were the tumour-to-pancreas ratios (Table 3 ).

\section{Dose calculation}

After applying ${ }^{177}$ Lu-DOTA-PEG 5 k-Lys-BN at a low molar amount of peptide $(0.3 \mathrm{nmol})$ in a single dose, the absorbed doses were calculated to be $0.36 \mathrm{~Gy} / \mathrm{MBq}$ for the murine kidney, $0.002 \mathrm{~Gy} / \mathrm{MBq}$ for the blood, $0.02 \mathrm{~Gy} / \mathrm{MBq}$ for the pancreas and $0.19 \mathrm{~Gy} / \mathrm{MBq}$ for the tumour. After the application of ${ }^{177} \mathrm{Lu}-\mathrm{DOTA}-\mathrm{PEG}_{5 \mathrm{k}^{-}}$ Lys-BN at a high amount of peptide $(3.0 \mathrm{nmol})$, however, the absorbed doses to the murine kidney, blood, pancreas and tumour were calculated to be 0.50, 0.002, 0.006 and $0.11 \mathrm{~Gy} / \mathrm{MBq}$, respectively. The estimate for an adult male resulted in absorbed doses to the kidney, blood and pancreas of 9.4, 0.4 and $21.3 \mathrm{~Gy} / \mathrm{GBq}$ $(0.3 \mathrm{nmol})$ and $12.3,0.4$ and $5.2 \mathrm{~Gy} / \mathrm{GBq}(3.0 \mathrm{nmol})$, respectively.

\section{Therapy studies}

The therapy study was performed according to the protocol shown in Table 1 . In total, 48 mice were included and divided into six groups of mice bearing PC-3 tumours (groups A to F; $n=6$ ) and three additional groups of mice without tumours (groups $\mathrm{G}$ to $\mathrm{I} ; n=4$ ). All groups of mice which received the ${ }^{177} \mathrm{Lu}$-labelled BN analogues $(\mathrm{C}$ to $\mathrm{F})$ clearly showed a reduction of tumour growth in comparison with groups A and B which received only $\mathrm{PBS}$ or unlabelled $\mathrm{BN}$ analogue. The treatment with the non-PEGylated ${ }^{177}$ Lu-labelled $\mathrm{BN}$ analogue (0.3 nmol; group F) significantly decreased the 

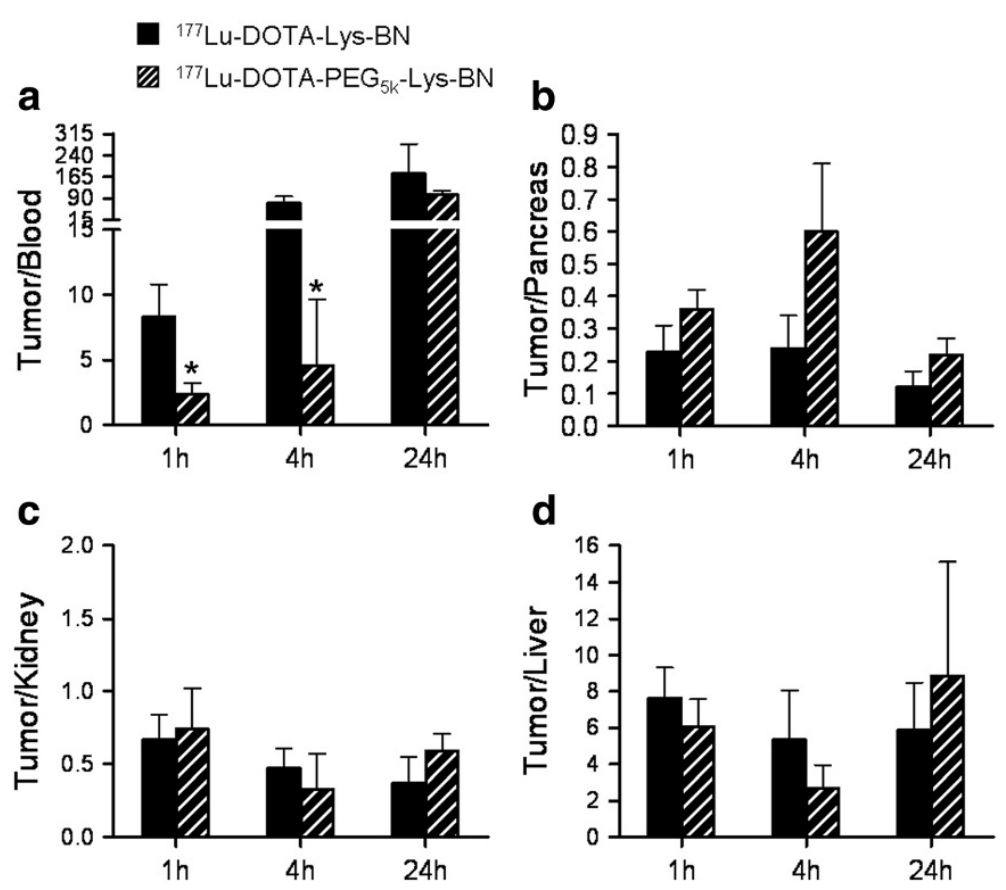

Figure 3 Tumour-to-non-target ratios. (a) Tumour-to-blood, (b) tumour-to-pancreas, (c) tumour-to-kidney and (d) tumour-to-liver ratios.

PC-3 tumour growth rate with respect to that of group A and exhibited an inhibition of $53 \% 3$ weeks after the first dose (Figures 5 and 6). The tumour growth inhibition was higher $(63 \%)$ with the ${ }^{177}$ Lu-DOTA-PEG ${ }_{5 k^{-}}$ Lys-BN analogue of high specific activity (group D).

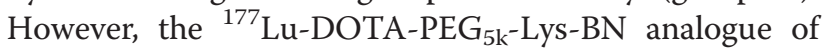
low specific activity (group $C$ ) exhibited only an inhibition of $36 \%$. The most effective tumour growth

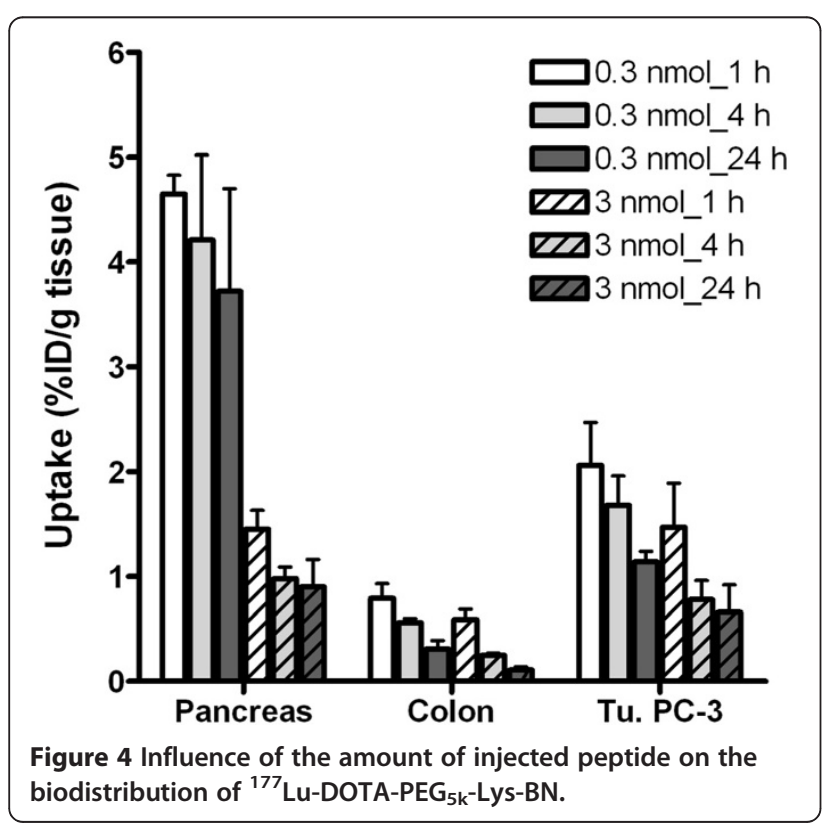

inhibition of $73 \%$ (3 weeks after the first dose) was observed when the second dose of the PEGylated BN analogue of high specific activity was applied 7 days after the first dose (group E; Figure 6). Mice of group B did not show an increased tumour growth with respect to group A (Figure 5), although BN agonists are known to have mitogenic characteristics.

\section{${ }^{99 m}$ TC-DMSA SPECT/CT imaging studies}

Forty-three days after therapy, the renal ${ }^{99 \mathrm{~m}}$ Tc-DMSA uptake of the treated animals (group $\mathrm{H}$ ) receiving the radiotracer of high specific activity was 76,397 counts/ kidney, whereas the uptake of the treated animals receiving the radiotracer of low specific activity (group I) was 74,949 counts/kidney. Seventy-one days after therapy, there was no significant difference in the renal ${ }^{99} \mathrm{~m}^{\mathrm{Tc}} \mathrm{C}$ DMSA uptake between groups G, H and I (51,344, 57,147 and 47,692 counts/kidney, respectively); 111 days after therapy, there was also no significant difference in the renal ${ }^{99 m}$ Tc-DMSA uptake between these three groups of mice.

\section{Discussion}

So far, only three optimised BN analogues, DOTA-8-AOC$\mathrm{BN}(7-14) \mathrm{NH}_{2}$, AMBA (DO3A- $\mathrm{CH}_{2} \mathrm{CO}-8$-aminooctanoylGln-Trp-Ala-Val-Gly-His-Leu-Met- $\mathrm{NH}_{2}$ ) and DOTAPESIN (DOTA-15-amino-4,7,10,13-tetraoxapentadecanoic acid-Gln-Trp-Ala-Val-Gly-His-Leu-Met- $\mathrm{NH}_{2}$ ), have been evaluated for PRRT [23-25]. These compounds were 
Table 3 Biodistribution (1 MBq/0.3 or $3.0 \mathrm{nmol}$ ) of ${ }^{177} \mathrm{Lu}$ DOTA-PEG $_{5 k}$-Lys-BN analogue in nude mice bearing PC-3 tumours

\begin{tabular}{|c|c|c|c|c|}
\hline \multirow[b]{3}{*}{ Tissue } & \multicolumn{4}{|c|}{${ }^{177}$ Lu-DOTA-PEG $5 k^{-L y s-B N}$} \\
\hline & \multicolumn{2}{|c|}{1 h p.i. } & \multicolumn{2}{|c|}{24 h p.i. } \\
\hline & $0.3 \mathrm{nmol}$ & $3.0 \mathrm{nmol}$ & $0.3 \mathrm{nmol}$ & $3.0 \mathrm{nmol}$ \\
\hline Blood & $0.51 \pm 0.09$ & $0.77 \pm 0.11^{*}$ & $0.02 \pm 0.00$ & $0.02 \pm 0.00$ \\
\hline Heart & $0.22 \pm 0.05$ & $0.31 \pm 0.09$ & $0.04 \pm 0.01$ & $0.05 \pm 0.01$ \\
\hline Lung & $0.92 \pm 0.59$ & $2.03 \pm 1.64$ & $0.44 \pm 0.32$ & $0.58 \pm 0.36$ \\
\hline Spleen & $0.45 \pm 0.11$ & $0.39 \pm 0.05$ & $0.40 \pm 0.06$ & $0.21 \pm 0.04$ \\
\hline Kidneys & $3.11 \pm 0.42$ & $3.92 \pm 0.59$ & $1.59 \pm 0.42$ & $2.12 \pm 0.21$ \\
\hline Pancreas & $4.65 \pm 0.18^{* *}$ & * $1.45 \pm 0.18$ & $3.72 \pm 0.98^{*}$ & $0.90 \pm 0.26$ \\
\hline Stomach & $0.42 \pm 0.09$ & $0.89 \pm 0.65$ & $0.16 \pm 0.03$ & $0.14 \pm 0.10$ \\
\hline Small intestine & $0.55 \pm 0.02$ & $0.78 \pm 0.39$ & $0.20 \pm 0.04^{*}$ & $0.10 \pm 0.02$ \\
\hline Colon & $0.79 \pm 0.14$ & $0.59 \pm 0.10$ & $0.31 \pm 0.08^{*}$ & $0.11 \pm 0.03$ \\
\hline Liver & $0.50 \pm 0.06$ & $0.64 \pm 0.07$ & $0.51 \pm 0.05$ & $0.46 \pm 0.02$ \\
\hline Muscle & $0.17 \pm 0.03$ & $0.20 \pm 0.05$ & $0.02 \pm 0.01$ & $0.02 \pm 0.00$ \\
\hline Bone & $0.21 \pm 0.03$ & $0.31 \pm 0.03$ & $0.23 \pm 0.03$ & $0.22 \pm 0.03$ \\
\hline Tumour & $2.06 \pm 0.41^{*}$ & $1.47 \pm 0.42$ & $1.14 \pm 0.10$ & $0.66 \pm 0.26$ \\
\hline Tumour-to-blood & $4.08 \pm 0.54$ & $1.89 \pm 0.42$ & $62.46 \pm 3.58$ & $36.24 \pm 13.73$ \\
\hline Tumour-to-liver & $4.11 \pm 0.67$ & $2.28 \pm 0.60$ & $2.78 \pm 0.21$ & $1.47 \pm 0.56$ \\
\hline Tumour-to-kidney & $0.67 \pm 0.14$ & $0.38 \pm 0.13$ & $0.62 \pm 0.07$ & $0.33 \pm 0.16$ \\
\hline Tumour-to-muscle & $12.26 \pm 4.01$ & $7.20 \pm 0.90$ & $55.89 \pm 32.86$ & $27.27 \pm 11.92$ \\
\hline Tumour-to-pancreas & $0.44 \pm 0.08$ & $1.01 \pm 0.23$ & $0.28 \pm 0.08$ & $0.62 \pm 0.22$ \\
\hline
\end{tabular}

${ }^{*} P<0.05$. ${ }^{* *} P<0.001$. Data in percentage of injected dose per gram of tissue $(\% \mathrm{ID} / \mathrm{g})$, expressed as mean \pm SD at 1 and $24 \mathrm{~h}$ p.i. $(n=3)$.

radiolabelled with the therapeutic radioisotopes ${ }^{177} \mathrm{Lu}$ or ${ }^{213} \mathrm{Bi}$ and showed anti-tumour effectiveness in mice with PC-3 xenografts. Regarding in vitro evaluation and biodistribution data, our ${ }^{177}$ Lu-DOTA-Lys-BN analogue showed pharmacokinetic properties which are comparable to those of the above-mentioned BN analogues, except for the higher tumour uptake and the better retention profile of AMBA and DOTA-PESIN. Therefore, we wanted to improve the radiotherapy relevant characteristics further by PEGylating ${ }^{177}$ Lu-DOTA-Lys-BN.

In vitro, time-dependent cell uptake and internalisation showed slower binding kinetics for the PEGylated $\mathrm{BN}$ analogue. These findings are in line with the results of PEGylating other biomolecules reported in the literature [31]. PEG is also reported to affect target association and dissociation rates of antibody fragments negatively [32]. These aspects may apply to our ${ }^{177} \mathrm{Lu}$ DOTA-PEG ${ }_{5 \mathrm{k}}$-Lys-BN and explain why binding affinity of this analogue in vitro was slightly reduced (Additional file 1), the steady state was reached later, and the total cell binding was lower in comparison with that of the non-PEGylated counterpart.

Previously, we could confirm that PEGylation improves the stability of BN toward enzymatic degradation [26]. In
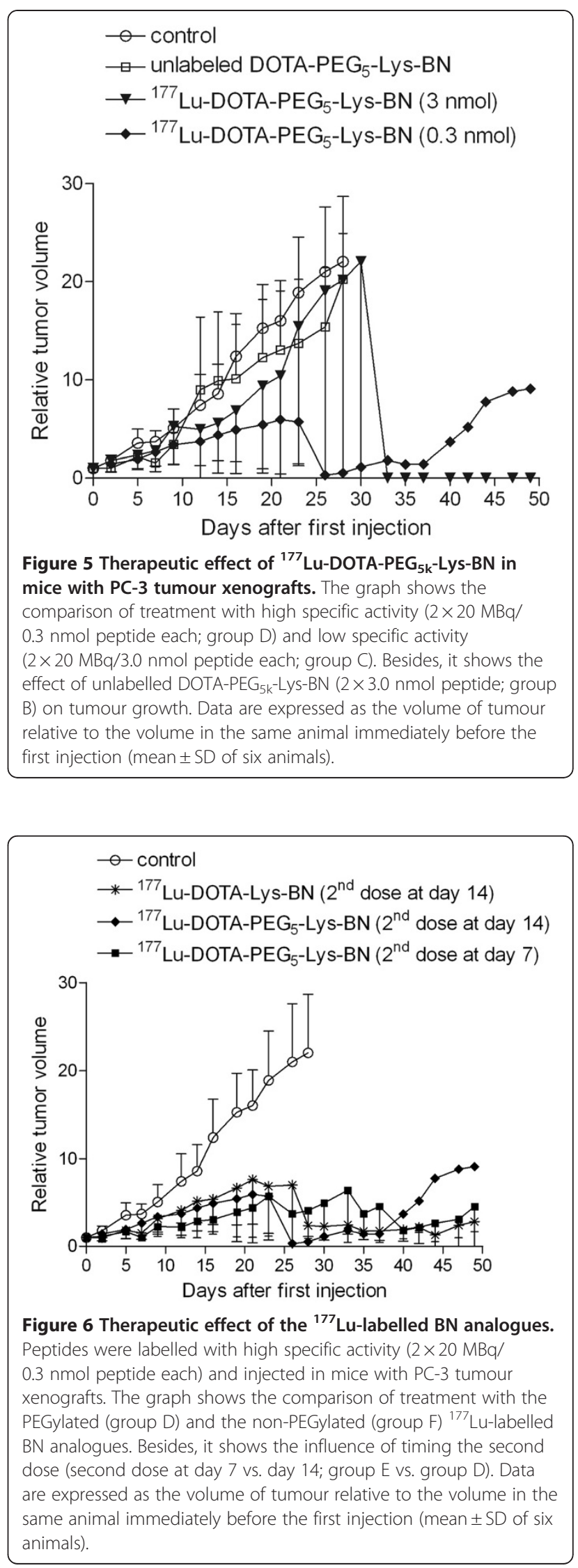
the case of DOTA-Lys-BN, conjugation of PEG Fk $_{k}$ also led to a considerable increase in stability in vitro (Figure 2). The half-life $\left(t_{1 / 2}\right)$ of ${ }^{177} \mathrm{Lu}-\mathrm{DOTA}-\mathrm{PEG}_{5 \mathrm{k}}$-Lys-BN in human plasma was 5.6-fold higher in comparison with that of non-PEGylated ${ }^{177}$ Lu-DOTA-Lys-BN. In comparison to ${ }^{177} \mathrm{Lu}$-AMBA, which is more stable in human plasma $\left(t_{1 / 2}=38.8 \mathrm{~h}\right)$ [23] than ${ }^{177} \mathrm{Lu}$-DOTA-PESIN $\left(t_{1 /}\right.$ ${ }_{2}=8.4 \mathrm{~h}$ ) [25], the in vitro half-life of ${ }^{177}$ Lu-DOTA-Lys$\mathrm{BN}$ in human plasma $\left(t_{1 / 2}=28.8 \mathrm{~h}\right)$ was in the same range but was markedly higher with the PEGylated BN analogue $\left(t_{1 / 2}=160.8 \mathrm{~h}\right)$.

The biodistribution data, in which $0.002 \mathrm{nmol}$ of ${ }^{177} \mathrm{Lu}-\mathrm{AMBA}$ and ${ }^{177} \mathrm{Lu}-\mathrm{DOTA}-8-\mathrm{AOC}-\mathrm{BN}(7-14)$ (HPLC purified) was injected per mouse [23], and the data of ${ }^{177}$ Lu-DOTA-PESIN (0.2 nmol peptide) [25] were compared with our biodistribution data, in which $0.075 \mathrm{nmol}$ of the ${ }^{177} \mathrm{Lu}$-labelled $\mathrm{BN}$ analogues were injected. This $0.075 \mathrm{nmol}$ is the nearest possible approximation to the $0.002 \mathrm{nmol}$ without HPLC purification, which is desired in clinics. In comparison with ${ }^{177} \mathrm{Lu}$ AMBA, our ${ }^{177}$ Lu-DOTA-Lys-BN showed an approximately fourfold lower kidney uptake $1 \mathrm{~h}$ p.i., whereas the kidney uptake of the ${ }^{177} \mathrm{Lu}$-DOTA-PEG $\mathrm{F}_{5 \mathrm{k}}$-Lys-BN analogue was 2.3 -fold lower at $1 \mathrm{~h}$ p.i. Both compounds showed a faster clearance from the kidneys within $24 \mathrm{~h}$ p.i. Kidney accumulation and washout of our ${ }^{177} \mathrm{Lu}$ DOTA-Lys-BN and ${ }^{177}$ Lu-DOTA-PEG ${ }_{5 k}$-Lys-BN were comparable to those of ${ }^{177}$ Lu-DOTA-PESIN $(3.8 \pm 0.34 \%$ $\mathrm{ID} / \mathrm{g}$ at $1 \mathrm{~h}$ p.i.), even though Gelofusine and polyglutamic acid were co-administered with ${ }^{177}$ Lu-DOTA-PESIN for the reduction of renal uptake [25]. Furthermore, the GI uptake was much lower with ${ }^{177}$ Lu-DOTA-Lys-BN and ${ }^{177} \mathrm{Lu}$-DOTA-PEG 5 k-Lys-BN at 1 and $24 \mathrm{~h}$ p.i. compared with that in ${ }^{177} \mathrm{Lu}-\mathrm{AMBA}$ (11.2\%ID and 5.8\% ID, respectively) and ${ }^{177} \mathrm{Lu}-\mathrm{DOTA}-8-\mathrm{AOC}-\mathrm{BN}(7-14) \quad(9.7 \%$ ID and $1.7 \%$ ID, respectively) [23]. However, the significantly higher blood level at $1 \mathrm{~h}$ p.i. after PEGylation might cause higher bone marrow toxicity and could therefore be a potential drawback of PEGylation.

${ }^{177}$ Lu-DOTA-PEG ${ }_{5 k}$-Lys-BN showed significantly higher tumour uptake at $1 \mathrm{~h}$ p.i. in comparison with the non-PEGylated counterpart. The higher enzymatic stability as well as the longer blood circulation may have compensated for the slower binding kinetics and the lower receptor affinity of DOTA-PEG ${ }_{5 k}-$ Lys-BN. In order to compare the cumulative radioactivity over $24 \mathrm{~h}$ of each conjugate in the tumour, the AUC value of ${ }^{177}$ Lu-DOTA-Lys-BN was arbitrarily set to 1 . The comparison showed a relative AUC value of $1.6(P<0.0006)$ for ${ }^{177} \mathrm{Lu}$-DOTA-PEG $5 \mathrm{k}$-Lys-BN.

The second hypothesis that PEGylation prolongs the tumour retention was also proven. Even though PEGylation lowered the tumour washout only slightly between 1 and $24 \mathrm{~h}$ p.i., there was more ${ }^{177} \mathrm{Lu}-\mathrm{DOTA}-\mathrm{PEG}_{5 \mathrm{k}}$-Lys-BN retained in the tumour between 0 and $24 \mathrm{~h}$ p.i. The extended tumour retention for the ${ }^{177} \mathrm{Lu}-\mathrm{DOTA}-\mathrm{PEG}_{5 \mathrm{~K}^{-}}$ Lys-BN might be explained by the improved enzymatic stability of the peptide derivative, and the extended retention might be due to the enhanced permeation and retention in the tumour. On the basis of the biodistribution data with ${ }^{177}$ Lu-AMBA [23] and ${ }^{177}$ Lu-DOTA-PESIN [25], both $\mathrm{BN}$ analogues showed higher tumour uptakes $(6.35 \pm 2.23 \% \mathrm{ID} / \mathrm{g}$ and $11.6 \pm 1.4 \% \mathrm{ID} / \mathrm{g}$ at $1 \mathrm{~h}$ p.i., respectively) and better retention profiles than our ${ }^{177} \mathrm{Lu}$-labelled $\mathrm{BN}$ analogues. However, compared to ${ }^{177} \mathrm{Lu}$-DOTA-8AOC-BN(7-14) [23] $(2.84 \pm 1.65 \% \mathrm{ID} / \mathrm{g}$ at $1 \mathrm{~h}$ p.i.), our ${ }^{177}$ Lu-DOTA-Lys-BN analogue showed a similar tumour uptake, but the uptake of ${ }^{177}$ Lu-DOTA-PEG ${ }_{5 k}$-Lys-BN was higher. This comparison, however, must be looked at with due care because the study designs differ insofar as different peptide amounts were injected.

The third hypothesis, i.e. that PEGylation improves tumour-to-non-target ratios, could partially be confirmed. The tumour-to-non-target ratios were rather similar for both derivatives. However, in comparison with the non-PEGylated BN analogue, the ${ }^{177}$ Lu-DOTA$\mathrm{PEG}_{5 \mathrm{k}}$-Lys-BN analogue exhibited a higher tumour uptake and a prolonged tumour retention which resulted in increased tumour-to-pancreas ratios at all time points and in higher tumour-to-liver and tumour-to-kidney ratios at $24 \mathrm{~h}$ p.i. (Figure 3).

Alongside PEGylation, the influence of the specific activity on biodistribution was evaluated. ${ }^{177} \mathrm{Lu}$-DOTAPEG $_{5 \mathrm{k}}$-Lys-BN injected at two different peptide amounts corresponding to the amount that was injected in the therapy studies ( 0.3 or $3.0 \mathrm{nmol}$, respectively) affected the uptake into receptor-expressing tissues. The amount of $0.3 \mathrm{nmol}$ was selected to approximate the $0.22 \mathrm{nmol}$ of the AMBA therapy study because these amounts of $0.3 \mathrm{nmol}$ have proven to be the limit for high specific labelling, i.e. the labelling is reproducible without any loss in yield. The amount of $3.0 \mathrm{nmol}$ however was selected because a preliminary study (data not presented) had suggested that peptide amounts in this range markedly reduce the uptake into non-target receptor positive tissues. In comparison with a low peptide amount, applying a high peptide amount resulted in a marked reduction in pancreas and colon uptake which would lower the risk of radiotoxic side effects induced by radionuclide therapy (Figure 4). However, the cumulative radioactivity in the tumour was significantly higher with a low peptide amount. The dosimetry showed that the absorbed dose into the tumour was 1.7-fold higher with the radiotracer of high specific activity, which would presumably indicate a higher anti-tumour effect. Furthermore, a lower accumulation in the kidneys within $24 \mathrm{~h}$ p.i. was observed with ${ }^{177}$ Lu-DOTA-PEG ${ }_{5 \mathrm{k}}$-Lys-BN at a low amount of peptide (Table 3), which would indicate a reduced risk of 
nephrotoxicity induced by radionuclide therapy. Thus, the incidence of BN-related toxicity after i.v. injection could be reduced using a low amount of peptide.

The radionuclide therapy studies (Table 1) showed a higher anti-tumour effectiveness with ${ }^{177}$ Lu-DOTA$\mathrm{PEG}_{5 \mathrm{k}}$-Lys-BN (group D) compared with ${ }^{177}$ Lu-DOTALys-BN (group F) (63\% vs. 53\% inhibition 3 weeks after the first dose, respectively; Figure 6). This is in accordance with the biodistribution data, which showed a higher tumour uptake and retention after PEGylation (Table 2). As comparative time point, we chose 3 weeks after the first dose, in order to evaluate the effectiveness of the different therapy protocols. This is the latest time point before several mice had to be euthanised upon fulfilling the endpoint criteria. Therefore, an interpretation after 3 weeks is not reliable since the groups represent only individual mice (Figures 5 and 6).

The therapy studies, in which the specific activity was varied (group $\mathrm{C}$ vs. group D), resulted in a markedly higher therapeutic efficiency when ${ }^{177} \mathrm{Lu}-\mathrm{DOTA}-\mathrm{PEG}_{5 \mathrm{k}^{-}}$ Lys-BN was applied at high specific activity (63\% vs. $36 \%$ inhibition 3 weeks after the first dose). The lower tumour accumulation of ${ }^{177} \mathrm{Lu}-\mathrm{DOTA}-\mathrm{PEG}_{5 \mathrm{k}}$-Lys-BN of low specific activity resulted in a proportionally faster tumour growth. We could demonstrate that the reduced efficacy is not caused by the tumour growth-promoting effect of the higher peptide amount since unlabelled

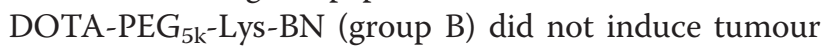
growth compared with the control group (Figure 5). These results are in line with previous observations reported in the literature [25]. The high specific therapy, as we have seen, was more efficient than the low specific, which is in accordance with the biodistribution studies which demonstrate that the uptake in GRPRexpressing tissues is highest for the lower peptide dose and is reduced with the higher peptide dose. This phenomenon is considered to be the result of partial saturation of receptors in the target tissues at higher peptide doses.

Furthermore, it can be assumed that an increase in specific activity would achieve at least the same therapeutic efficiency as low specific activity, but the dosage injected would be lower.

Preliminary therapy studies (Additional file 1: Figure S8), as expected, showed that the administration of two doses $(2 \times 20 \mathrm{MBq}=40 \mathrm{MBq})$ was more effective in tumour growth inhibition than application of a single dose $(20 \mathrm{MBq})$. As shown with in vitro autoradiography (Additional file 1: Figure S9), there was no long-lasting down-regulation of $\mathrm{BN}_{2} / \mathrm{GRP}$ receptors in the tumour after treatment, which suggests that it is sensible to apply a multiple dosage. Therefore, two different twodose regimens were evaluated in the current therapy studies. Applying the second dose at day 14 was chosen to match the AMBA therapy study. The preliminary study showed that the tumour started to grow after 14 days regardless of the second injection. Since the cause for this might have been that the tumour was already too large to respond to the treatment, the second application was introduced at day 7 in order to hit the tumour in an earlier state. The therapeutic efficiency was increased even further when the second dose of ${ }^{177}$ Lu-DOTA-PEG - -Lys-BN (group E) was applied 7 days after the first dose instead of 14 days (73\% vs. 63\% inhibition at day 21) (group D).

Comparing our study with the therapy studies with ${ }^{177} \mathrm{Lu}$-AMBA [23], ${ }^{177} \mathrm{Lu}$-DOTA-PESIN [25] $(2 \times 28 \mathrm{MBq}$, $0.2 \mathrm{nmol}$ ) and ${ }^{177}$ Lu-DOTA-8-AOC-BN(7-14) [24], we found the tumour growth inhibition with our PEGylated BN analogue to be lower than with AMBA (approximately $73 \%$ vs. approximately $82 \%$ ) but higher than with DOTAPESIN (approximately $73 \%$ vs. approximately $45 \%$ ) and roughly the same as with ${ }^{177} \mathrm{Lu}$-DOTA-8-AOC-BN(7-14) (approximately 73\% vs. approximately 79\%) 3 weeks after the first dose. However, such a comparison is not fully conclusive since these therapy studies differ in tumour size at the beginning of therapy, injected peptide amount, administered radiation dose and injection interval.

In order to assess the risk for nephrotoxicity related to radionuclide therapy, a rough dosimetric estimate for an adult male was performed based on the biodistribution, in which 0.3 or $3.0 \mathrm{nmol}$ of the ${ }^{177} \mathrm{Lu}$-DOTA-PEG $5_{5 \mathrm{k}^{-}}$ Lys-BN analogue were applied. This estimate implies that an administration of approximately $2 \mathrm{GBq}$ of either low or high specific ${ }^{177}$ Lu-DOTA-PEG ${ }_{5 k}$-Lys-BN analogue would result in absorbed kidney doses of approximately 18.8 or $24.6 \mathrm{~Gy}$, respectively. These doses would not exceed the acceptable safe limit of 23 to $27 \mathrm{~Gy}$ [33]. The administration of $2 \mathrm{GBq}$ would supposedly be necessary to reach a tumour dose of 50 Gy (supposed that the absorbed dose into the pancreas corresponds to the tumour dose), which is needed for treatment as external beam radiation therapy and brachytherapy data suggest [34-36]. A further step in the risk assessment was ${ }^{99 \mathrm{~m}} \mathrm{Tc}-$ DMSA scintigraphy which showed that there was no kidney damage in the mice treated with high or low specific ${ }^{177} \mathrm{Lu}$-DOTA-PEG - -Lys-BN analogue (group $\mathrm{H}$ and I) since there was no significant difference in renal ${ }^{99 \mathrm{~m}}$ Tc-DMSA uptake of control and treated mice. Besides, serum analysis confirmed the absence of renal toxicity (Additional file 1).

\section{Conclusions}

PEGylation, increasing the specific activity of the radiolabelled bombesin analogue and shortening the injection interval proved to be effective strategies to enhance the radiotherapeutic efficacy and to provide a favourable risk-profile at the same time. Tumour targeting 
was optimised and tumour retention was prolonged with the ${ }^{177}$ Lu-DOTA-PEG ${ }_{5 k}$-Lys-BN analogue of high specific activity. The estimate of the absorbed doses for an adult male implied that the absorbed kidney doses would lie below the threshold of kidney damage. Taking the positive features into account, which have been observed in this study, we believe that PEGylation of small molecular weight radiopharmaceuticals is an efficient strategy to improve their potential for a successful application in targeted radionuclide therapy.

\section{Additional file}

\section{Additional file 1: Synthetic details of the PEGylation of the DOTA-} Lys-BN analogue, experimental details of the octanol/PBS partition coefficient $(\log D)$ determination, details of the apparent receptor affinity $\left(\mathrm{IC}_{50}\right)$ and serum analyses, results of the preliminary therapy study and the results of the in vitro autoradiography of tumour sections are presented in the Additional file. References [23,25,37-39] are included in the Additional file 1.

\section{Competing interests}

The authors declare that they have no competing interests.

\section{Acknowledgements}

The authors thank Dr. Alexander Hohn, Mr. Alain Blanc and Ms. Olga Gasser for technical assistance. They also thank Ms. Elisbeth Rogg (Laboratory of Veterinary Medicine at the University of Zurich) for measuring plasma samples. This work was supported by a grant from the Swiss Cancer League Nr. KLS-02040-02-2007.

\section{Author details}

${ }^{1}$ Paul Scherrer Institute, Center for Radiopharmaceutical Sciences ETH-PSIUSZ, Villigen-PSI 5232, Switzerland. ${ }^{2}$ Department of Organic Chemistry, Vrije Universiteit Brussel, Brussels 1050, Belgium. ${ }^{3}$ Department of Chemistry and Applied Biosciences, ETH Zurich, Zurich 8093, Switzerland.

\section{Authors' contributions}

SD participated in the whole study and drafted the manuscript. CM participated in the studies concerning stability, biodistribution, therapy and ${ }^{99 m}$ TC-DMSA SPECT/CT imaging, proofread the manuscript and made suggestions. EGG participated in the biodistribution studies. PB contributed to the dose calculation. VM, LB and DAT carried out the peptide synthesis. RS supervised the study and proofread the manuscript. All authors read and approved the final manuscript.

Received: 25 February 2012 Accepted: 9 June 2012

Published: 9 June 2012

\section{References}

1. Nagalla SR, Barry BJ, Falick AM, Gibson BW, Taylor JE, Dong JZ, Spindel ER: There are three distinct forms of bombesin: identification of [Leu13] bombesin, [Phe13]bombesin, and [Ser3, Arg10, Phe13]bombesin in the frog Bombina orientalis. J Biol Chem 1996, 271:7731-7737.

2. Reubi JC, Wenger S, Schmuckli-Maurer J, Schär JC, Gugger M: Bombesin receptor subtypes in human cancers: detection with the universal radioligand ${ }^{125} \mathrm{I}-\left[\mathrm{D}-\mathrm{TYR}^{6}\right.$, beta-ALA $\left.{ }^{11}, \mathrm{PHE}^{13}, \mathrm{NLE}^{14}\right]$ bombesin(6-14). Clin Cancer Res 2002, 8:1139-1146.

3. Gugger M, Reubi JC: Gastrin-releasing peptide receptors in nonneoplastic and neoplastic human breast. Am J Pathol 1999, 155:2067-2076.

4. Markwalder R, Reubi JC: Gastrin-releasing peptide receptors in the human prostate: relation to neoplastic transformation. Cancer Res 1999, 59:1152-1159.

5. Moody TW, Cuttitta F: Growth factor and peptide receptors in small cell lung cancer. Life Sci 1993, 52:1161-1173.
6. Lambert B, Cybulla M, Weiner SM, Van De Wiele C, Ham H, Dierckx RA, Otte A: Renal toxicity after radionuclide therapy. Radiat Res 2004, 161:607-611.

7. Kwekkeboom DJ, Mueller-Brand J, Paganelli G, Anthony LB, Pauwels S, Kvols LK, O'Dorisio TM, Valkema R, Bodei L, Chinol M, Mäcke HR, Krenning EP: Overview of results of peptide receptor radionuclide therapy with 3 radiolabeled somatostatin analogs. J Nucl Med 2005, 46(Suppl 1):62S-66S.

8. Valkema R, Pauwels SA, Kvols LK, Kwekkeboom DJ, Jamar F, de Jong M, Barone R, Walrand S, Kooij PP, Bakker WH, Lasher J, Krenning EP: Long-term follow-up of renal function after peptide receptor radiation therapy with ${ }^{90} \mathrm{Y}_{\text {-DOTA }}{ }^{0}$, Tyr ${ }^{3}$-octreotide and ${ }^{177}$ Lu-DOTA ${ }^{0}$, Tyr ${ }^{3}$-octreotate. J NuCl Med 2005, 46(Suppl 1):83S-91S

9. Hoffman TJ, Gali H, Smith CJ, Sieckman GL, Hayes DL, Owen NK, Volkert WA: Novel series of ${ }^{111}$ In-labeled bombesin analogs as potential radiopharmaceuticals for specific targeting of gastrin-releasing peptide receptors expressed on human prostate cancer cells. J Nucl Med 2003, 44:823-831.

10. Zhang H, Chen J, Waldherr $\mathrm{C}$, Hinni K, Waser B, Reubi JC, Mäcke HR: Synthesis and evaluation of bombesin derivatives on the basis of panbombesin peptides labeled with indium-111, lutetium-177, and yttrium90 for targeting bombesin receptor-expressing tumors. Cancer Res 2004, 64:6707-6715.

11. Schroeder RP, Müller $C$, Reneman $S$, Melis ML, Breeman WA, de Blois E, Bangma $\mathrm{CH}$, Krenning EP, van Weerden WM, de Jong M: A standardised study to compare prostate cancer targeting efficacy of five radiolabelled bombesin analogues. Eur J Nucl Med Mol Imaging 2010, 37:1386-1396.

12. Smith CJ, Volkert WA, Hoffman TJ: Gastrin releasing peptide (GRP) receptor targeted radiopharmaceuticals: a concise update. Nucl Med Biol 2003, 30:861-868.

13. Nock B, Nikolopoulou A, Chiotellis E, Loudos G, Maintas D, Reubi JC, Maina T: $\left.{ }^{99 \mathrm{~m}} \mathrm{Tc}\right]$ Demobesin 1, a novel potent bombesin analogue for GRP receptor-targeted tumour imaging. Eur I Nucl Med Mol Imaging 2003, 30:247-258.

14. Garcia Garayoa E, Schweinsberg C, Maes V, Brans L, Bläuenstein P, Tourwe $D A$, Schibli R, Schubiger PA: Influence of the molecular charge on the biodistribution of bombesin analogues labeled with the $\left.{ }^{99 \mathrm{~m}} \mathrm{Tc}(\mathrm{CO})_{3}\right]-$ core. Bioconjug Chem 2008, 19:2409-2416.

15. Schweinsberg C, Maes V, Brans L, Bläuenstein P, Tourwe DA, Schubiger PA Schibli R, Garcia Garayoa E: Novel glycated [ $\left.{ }^{99 \mathrm{~m}} \mathrm{Tc}(\mathrm{CO})_{3}\right]$-labeled bombesin analogues for improved targeting of gastrin-releasing peptide receptorpositive tumors. Bioconjug Chem 2008, 19:2432-2439.

16. Honer M, Mu L, Stellfeld T, Graham K, Martic M, Fischer CR, Lehmann L, Schubiger PA, Ametamey SM, Dinkelborg L, Srinivasan A, Borkowski S: ${ }^{18} \mathrm{~F}$ labeled bombesin analog for specific and effective targeting of prostate tumors expressing gastrin-releasing peptide receptors. J Nucl Med 2011, 52:270-278.

17. Mu L, Honer M, Becaud J, Martic M, Schubiger PA, Ametamey SM, Stellfeld T, Graham K, Borkowski S, Lehmann L, Dinkelborg L, Srinivasan A: In vitro and in vivo characterization of novel ${ }^{18} \mathrm{~F}$-labeled bombesin analogues for targeting GRPR-positive tumors. Bioconjug Chem 2010, 21:1864-1871.

18. Höhne A, Mu L, Honer M, Schubiger PA, Ametamey SM, Graham K, Stellfeld T, Borkowski S, Berndorff D, Klar U, Voigtmann U, Cyr JE, Friebe M, Dinkelborg L, Srinivasan A: Synthesis, ${ }^{18} \mathrm{~F}$-labeling, and in vitro and in vivo studies of bombesin peptides modified with silicon-based building blocks. Bioconjug Chem 2008, 19:1871-1879.

19. Schuhmacher J, Zhang H, Doll J, Mäcke HR, Matys R, Hauser H, Henze M, Haberkorn U, Eisenhut M: GRP receptor-targeted PET of a rat pancreas carcinoma xenograft in nude mice with a ${ }^{68} \mathrm{Ga-labeled}$ bombesin(6-14) analog. J Nucl Med 2005, 46:691-699.

20. Dimitrakopoulou-Strauss A, Hohenberger P, Haberkorn U, Mäcke HR Eisenhut M, Strauss LG: ${ }^{68}$ Ga-labeled bombesin studies in patients with gastrointestinal stromal tumors: comparison with ${ }^{18}$ F-FDG. J NuCl Med 2007, 48:1245-1250.

21. Lears KA, Ferdani R, Liang K, Zheleznyak A, Andrews R, Sherman CD, Achilefu S, Anderson CJ, Rogers BE: In vitro and in vivo evaluation of ${ }^{64} \mathrm{Cu}-$ labeled SarAr-bombesin analogs in gastrin-releasing peptide receptorexpressing prostate cancer. J Nucl Med 2011, 52:470-477.

22. Schroeder RP, van Weerden WM, Bangma C, Krenning EP, de Jong M: Peptide receptor imaging of prostate cancer with radiolabelled bombesin analogues. Methods 2009, 48:200-204.

23. Lantry LE, Cappelletti E, Maddalena ME, Fox JS, Feng W, Chen J, Thomas R, Eaton SM, Bogdan NJ, Arunachalam T, Reubi JC, Raju N, Metcalfe EC, 
Lattuada L, Linder KE, Swenson RE, Tweedle MF, Nunn AD: ${ }^{177}$ Lu-AMBA: synthesis and characterization of a selective ${ }^{177}$ Lu-labeled GRP-R agonist for systemic radiotherapy of prostate cancer. J Nucl Med 2006, 47:1144-1152.

24. Johnson CV, Shelton T, Smith CJ, Ma L, Perry MC, Volkert WA, Hoffman TJ: Evaluation of combined ${ }^{177}$ Lu-DOTA-8-AOC-BBN(7-14) $\mathrm{NH}_{2}$ GRP receptortargeted radiotherapy and chemotherapy in $\mathrm{PC}-3$ human prostate tumor cell xenografted SCID mice. Cancer Biother Radiopharm 2006, 21:155-166.

25. Wild D, Frischknecht M, Zhang H, Morgenstern A, Bruchertseifer F, Boisclair J, Provencher-Bolliger A, Reubi JC, Mäcke HR: Alpha- versus beta-particle radiopeptide therapy in a human prostate cancer model ${ }^{213}$ Bi-DOTA-PESIN and ${ }^{213}$ Bi-AMBA versus ${ }^{177}$ Lu-DOTA-PESIN). Cancer Res 2011, 71:1009-1018.

26. Däpp S, García-Garayoa E, Maes V, Brans L, Tourwé DA, Müller C, Schibli R: PEGylation of ${ }^{99 \mathrm{~m}} \mathrm{Tc}$-labeled bombesin analogues improves their pharmacokinetic properties. Nucl Med Biol 2011, 38:997-1009.

27. Kwekkeboom DJ, de Herder WW, Kam BL, van Eijck CH, van Essen M, Kooij PP, Feelders RA, van Aken MO, Krenning EP: Treatment with the radiolabeled somatostatin analog $\left[{ }^{177}{ }^{1}\right.$ Lu-DOTA ${ }^{0}$, Tyr $\left.{ }^{3}\right]$ octreotate: toxicity, efficacy, and survivalJ Clin Oncol 2008, 26:2124-2130.

28. Valkema R, Pauwels S, Kvols LK, Barone R, Jamar F, Bakker WH, Kwekkeboom DJ, Bouterfa $\mathrm{H}$, Krenning EP: Survival and response after peptide receptor radionuclide therapy with $\left[{ }^{90} \mathrm{Y}\right.$-DOTA ${ }^{0}$, Tyr $\left.{ }^{3}\right]$ octreotide in patients with advanced gastroenteropancreatic neuroendocrine tumors. Semin Nucl Med 2006, 36:147-156.

29. Kwekkeboom DJ, Bakker WH, Kooij PP, Konijnenberg MW, Srinivasan A, Erion Jl, Schmidt MA, Bugaj JL, de Jong M, Krenning EP: [177 Lu-DOTA ${ }^{0}$ Tyr $\left.{ }^{3}\right]$ octreotate: comparison with [111 In-DTPA ${ }^{0}$ ]octreotide in patients. Eur J Nucl Med 2001 , 28:1319-1325.

30. Larsson E, Strand S-E, Ljungberg M, Jönsson B-A: Mouse S-factors based on Monte Carlo simulations in the anatomical realistic Moby phantom for internal dosimetry. Cancer Biother Radiopharm 2007, 22:438-442.

31. Harris JM, Chess RB: Effect of pegylation on pharmaceuticals. Nat Rev Drug Discov 2003, 2:214-221.

32. Kubetzko S, Sarkar CA, Pluckthun A: Protein PEGylation decreases observed target association rates via a dual blocking mechanism. Mol Pharmacol 2005, 68:1439-1454.

33. Bodei L, Cremonesi M, Ferrari M, Pacifici M, Grana CM, Bartolomei M, Baio SM, Sansovini M, Paganelli G: Long-term evaluation of renal toxicity after peptide receptor radionuclide therapy with ${ }^{90} \mathrm{Y}$-DOTATOC and ${ }^{177}$ Lu-DOTATATE: the role of associated risk factors. Eur J Nucl Med Mol Imaging 2008, 35:1847-1856.

34. Isacsson U, Nilsson K, Asplund S, Morhed E, Montelius A, Turesson I: A method to separate the rectum from the prostate during proton beam radiotherapy of prostate cancer patients. Acta Oncol 2010, 49:500-505.

35. Jabbari S, Weinberg VK, Kaprealian T, Hsu IC, Ma L, Chuang C, Descovich M, Shiao S, Shinohara K, Roach lii M, Gottschalk AR: Stereotactic body radiotherapy as monotherapy or post-external beam radiotherapy boost for prostate cancer: technique, early toxicity, and PSA response. Int J Radiat Oncol Biol Phys 2012, 82:228-234.

36. Demanes DJ, Martinez AA, Ghilezan M, Hill DR, Schour L, Brandt D, Gustafson G: High-dose-rate monotherapy: safe and effective brachytherapy for patients with localized prostate cancer. Int J Rad Oncol Biol Phys 2011, 81:1286-1292.

37. Garcia Garayoa E, Rüegg D, Bläuenstein P, Zwimpfer M, Khan IU, Maes V, BeckSickinger AG, Tourwé DA, Schubiger PA: Chemical and biological characterization of new $\operatorname{Re}(\mathrm{CO})_{3} /\left[^{99 \mathrm{~m}} \mathrm{Tc}\right](\mathrm{CO})_{3}$ bombesin analogues. Nucl Med Biol 2007, 34:7-28.

38. Pillarsetty N, Cai S, Ageyeva L, Finn RD, Blasberg RG: Synthesis and evaluation of $\left[{ }^{18} \mathrm{~F}\right]$ labeled pyrimidine nucleosides for positron emission tomogra phy imaging of herpes simplex virus 1 thymidine kinase gene expression. J Med Chem 2006, 49:5377-5381.

39. La Bella R, Garcia-Garayoa E, Bahler M, Blauenstein P, Schibli R, Conrath P, Tourwé D, Schubiger PA: A ${ }^{99 \mathrm{~m}} \mathrm{TC}(\mathrm{I})$-postlabeled high affinity bombesin analogue as a potential tumor imaging agent. Bioconjug Chem. 2002, 13:599-604.

doi:10.1186/2191-219X-2-24

Cite this article as: Däpp et al:: PEGylation, increasing specific activity and multiple dosing as strategies to improve the risk-benefit profile of targeted radionuclide therapy with ${ }^{177}$ Lu-DOTA-bombesin analogues. EJNMMI Research 2012 2:24.

\section{Submit your manuscript to a SpringerOpen ${ }^{\circ}$ journal and benefit from:}

- Convenient online submission

$\checkmark$ Rigorous peer review

- Immediate publication on acceptance

- Open access: articles freely available online

- High visibility within the field

- Retaining the copyright to your article

Submit your next manuscript at $\gg$ springeropen.com 